\title{
A Community Needs Assessment of the Physical Activity and Food Environment in a Predominantly Hispanic U.S. City
}

Lebron $\mathrm{C}^{1}$, Stoutenberg $\mathrm{M}^{2}$, Portacio $\mathrm{F}^{2}$, Zollinger $\mathrm{TW}^{3}$

Cynthia Lebron, MPH, Sr. Clinical Research Coordinator, Jay Weiss Institute for Health Equity at Sylvester Cancer Center

1120 NW 14 ST, Miami, FL 33136

Phone: 305-243-4146

Fax: 305-243-3651

clebron@med.miami.edu

Mark Stoutenberg, $\mathrm{PhD}, \mathrm{MSPH}$

Research Assistant Professor

University of Miami Miller School of Medicine

1120 NW 14 ST, Miami, FL 33136

Phone: (305) 243-8949

MStoutenberg@,med.miami.edu

Francia Portacio

Department of Public Health Sciences, University of Miami Miller School of Medicine

fportacio@med.miami.edu

Terrell W. Zollinger, DrPH

Professor Emeritus

Indiana University Richard M. Fairbanks School of Public Health

714 N. Senate Avenue, Suite 250

Indianapolis, IN 46202

Office: (317) 278-0307

Corresponding Author:

Mark Stoutenberg

\section{Acknowledgement}

This research was supported by the ACSM American Fitness Index®, a program of the American College of Sports Medicine Foundation, with funding support from the Anthem Foundation.

Dr. Stoutenberg is supported by Grant Number 1KL2TR000461 of the Miami Clinical and Translational Science Institute from the National Center for Advancing Translational Sciences and the National Institute on Minority Health and Health Disparities. Its contents are solely the responsibility of the authors and do not represent the official views of the National Institutes of Health. 


\begin{abstract}
Hispanics suffer disproportionately from preventable health conditions that are impacted by physical activity and poor dietary habits. The social and environmental factors of the community that they live in have the potential to profoundly influence their lifestyle. Although there has been a multitude of research conducted in Hispanic populations, a better understanding of specific community needs is essential to inform future strategic plans. In this study, a needs assessment was conducted in Hialeah, Florida, a community with the highest percentage of Cubans and Cuban Americans in the US. Interviews were conducted with community stakeholders, as well as brief survey conducted among representative community members, to determine how the physical activity and nutrition environments influence the health of the city. Community stakeholders were concerned with how cultural influences, the city's walkability, and limited healthy food options serve as a major barrier to residents achieving healthy lifestyles. At the same time, community members believed that a variety of available healthy food options and resources for physical activity were available. However, community members reported that healthy food options were expensive and they were unaware of community programs that encouraged health promotion. Both community members and stakeholders reported that the local park system was an asset to healthy living in Hialeah, while traffic issues and a lack of walkability were major barriers to healthy lifestyles. These findings may be valuable in informing city officials of the community's needs and highlight pathways to enhance the health and wellness of the residents of Hialeah.
\end{abstract}

Keywords: Hispanics, community needs, physical activity, nutrition, environmental factors 


\section{Introduction}

Hispanics are currently the largest minority group in the U.S. [1] and are expected to represent one-third of the U.S. population by 2060 [2]. Results from the Hispanic Community Health Study/Study of Latinos, the largest comprehensive study of U.S. Hispanics to date with over 16,000 participants, found that 1 in 3 Hispanic individuals have prediabetes, and among those with diabetes, one third were unaware of their condition [3]. Similarly, the prevalence of metabolic syndrome in Hispanic individuals has been reported to be as high as $34 \%$ and $36 \%$ in men and women, respectively [4]. Hypertension, high cholesterol, obesity, and smoking are also exceedingly common, with two thirds of older Hispanics having two or more of these risk factors [3]. These health conditions and risk factors are heavily influenced by the environmental factors and social determinants of this population [5]. In the U.S., Hispanics have the highest percentage of adults who have not completed high school (37.7\%) and are living below the federal poverty line $(16.0 \%)$ when compared to other racial/ethnic groups [5]. Educational attainment and income level provide knowledge and access to resources that can protect individuals from unfavorable health outcomes [5]. As a result of low levels of education and income, Hispanics are more likely to be uninsured than any other racial/ethnic group [6], which can lead to delayed or forgoing of needed health care [7].

Hispanics experience greater levels of disparity in health status and physical activity [7]. Overweight and obesity is more prevalent among Hispanic adults when compared to non-Hispanic blacks and whites [8], affecting more than 3 in 4 Hispanics [9]. This is of particular concern as obesity is associated with a considerable increase in cardiovascular disease risk [10]. When compared to non-Hispanic white adults, Hispanic adults were the less likely to participate in 
aerobic and muscle strengthening exercises and less likely to report being in excellent or very good health status [7].

In addition to having an understanding of Hispanic health at a population level, it is also imperative to learn more about the specific factors that influence Hispanic health across distinct communities and backgrounds. Social, cultural, and demographic differences exist across Hispanic populations living in different areas of the U.S. (e.g. Mexican Americans living in California and Texas as compared to Cubans living in Florida) [11]. Thus, having knowledge of the specific lifestyle habits of a particular Hispanic community can help identify ways to better serve its local members. In this regard, Hialeah is a unique city in Florida with over 224,000 residents, of which approximately 95\% are Hispanic [12]. Hialeah has the highest percentage of Cuban and Cuban American residents in the U.S. [13] and has the second highest prevalence of Spanish speaking individuals [14]. In a national study of 100 most populated cities in the U.S., Hialeah was ranked as the fifth worst locale for an active lifestyle [15] and over $30 \%$ of the residents of Hialeah reported being in poor to fair health, with high levels of self-reported hypertension, depression, and smoking, as well as exceedingly low levels of physical activity; all ranking among the worst rates when compared with neighboring communities in South Florida [16].

To help community leaders in Hialeah address these health problems, a needs assessment was conducted by interviewing key community stakeholders and residents. A community needs assessment can be useful in identifying the strengths and weaknesses of a community and the resources available to address those needs [17]. By contributing to a needs assessment, community members feel empowered to voice their concerns to ensure effective change. Additionally, the 
inclusion of key stakeholders can provide examples of how local organizations are meeting the needs and demands of their community [18]. This assessment will provide a framework for developing an understanding of community concerns, which can then serve as a foundation for developing strategic plans and solutions to address the identified problems. The purpose of this study was to assess the various physical activity and nutrition environments in the City of Hialeah to determine how these factors may be influencing the health its residents.

\section{Methods}

The Hialeah community needs assessment consisted of two major components: 1) identifying and interviewing key community stakeholders to elicit their experiences and perceptions regarding ways to improve the health, wellness, and quality of life of Hialeah residents, and 2) surveying a sample of community members from a diverse array of public and private sectors to assess their perceptions of physical activity and dietary choices available to them in Hialeah. The University of Miami Institutional Review Board (IRB) approved the use and publication of the de-identified data collected as part of this community needs assessment."

\section{Community Stakeholder Interviews}

Community members who were serving in leadership positions in organizations and/or institutions that either operated in or served the City of Hialeah were identified and asked to participate in a structured interview with a member of the research team. Community leaders were selected based on their experience and knowledge of the health and wellness of Hialeah, their insights into past and current programs and the successes and obstacles faced by these programs, and their familiarity with local partners (e.g., local businesses and organizations) who played a role in determining the health of the community. A list of these community leaders was developed by the 
research team consisting of community leaders from all major sectors in the city, such as the local police and fire departments, the Parks and Recreation Department, other government agencies, local businesses, as well as faith-based and non-profit organizations. Additional key community stakeholders were identified on an ongoing basis throughout the needs assessment process.

An introductory email was sent to these community leaders during the spring of 2014 requesting an individual interview. A research team member followed up the initial email with further emails and telephone calls to arrange appointments with as many community stakeholders as possible. Inperson interviews were attempted first and scheduled telephone interview appointments only when in-person appointments were not feasible. Prior to the scheduled interviews, a copy of the interview questions was emailed to the community stakeholders to enable them to prepare for the interview. A total of 34 key community stakeholders were contacted and invited to participate in the study; 21 key community stakeholders participated in the interview process. Twenty of the 21 interviews were conducted in English.

The interview questions were originally developed by the Indiana University Bowen Research Center for use in the American Fitness Index Technical Assistance pilot project in 2011. The original set of 12 questions was modified and expanded to 22 structured questions. Questions focused on the stakeholders' opinions of the city, the residents, and community leadership goals. Interview responses were collated together, summarized, common themes were identified, and the number of times stakeholders provided similar responses to each question was tabulated.

\section{Community Member Surveys}


A 21-question tool, used to survey the community members, was constructed from the five key strategies outlined in the "Accelerating Progress in Obesity Prevention" [19]. These key strategies included: the physical activity environment, the food environment, the message environment, school systems, and workplace wellness. An additional set of questions were added to assess the community members' levels of awareness of local initiatives, the programs that they conducted, and if the community members had participated in any of these programs. The majority of the questions used a 5-point Likert-type scale that assessed the community members' level of agreement with a series of statements. Three additional open-ended questions explored: 1) locations where community members sought out healthy food choices, 2) programs and/or opportunities in Hialeah they were aware of that taught children and adults about healthy living, and 3) the types of programs and/or opportunities they wanted to teach children and adults about healthy living.

The survey was administered by members of the research team in either English or Spanish at the preference of the community members. The questionnaires were completed by four to eight community members in 13 different locations in Hialeah. Due to a limited number of employees/customers, only a single survey was completed at a $14^{\text {th }}$ location. A list of locations where the community member survey was administered is included in Table 1 . These locations were purposively selected to match the sites where community stakeholder interviews were completed and to ensure that the community members who participated in the survey were as demographically representative of the community as possible. At each location, research team members attempted to select individuals from all gender and age categories. Community members were eligible to participate in the survey if they were: 1) current residents of the City of Hialeah, 
2) at least 18 years of age, and 3) were either employees or customers at that location. Community members were excluded from the study if they were not capable of completing the survey due to mental or cognitive impairment or had recently moved to Hialeah and were unfamiliar with the city and its programs. The survey took six to eight minutes to complete and respondents were provided with a $\$ 10$ gift card to compensate them for their time.

Survey responses were coded and entered into an excel spreadsheet where counts and percentages were computed for each question. Additionally, community members' responses were stratified by age, gender, place of birth, number of years residing in Hialeah, and whether respondents had school aged children. These groups were compared for differences using chi-square tests. The open-ended responses were collated together to enable an item analysis to identify common themes, as well as the range of responses.

\section{Results}

\section{Community Stakeholder Responses}

When asked what the key community stakeholders believed were the major health problems facing the City of Hialeah, they cited lack of healthcare and high disease rates 30 times, followed by mental illness and addictions (12 times), overweight/obesity (11 times), and the aging population (6 times). When asked what they thought people of Hialeah found important in respect to their health, access to healthcare was cited 14 times, followed by obesity (10 times), employment/financial stability (5 times), and quality of life (4 times). 
The most frequently mentioned supporters of healthy living in Hialeah were community organizations (23 times), community resources (21 times), and cultural influences or interpersonal resources, such as social connectivity (4 times). The greatest barriers to healthy living in Hialeah were reported to be cultural dietary influences ( 20 times), followed by the physical environment (11 times), lack of education/awareness ( 9 times), economic barriers ( 7 times), mental health issues (4 times), and lack of healthcare (4 times).

When the community stakeholders were asked about the ways in which residents of Hialeah were at the greatest risk for obesity they cited: the food environment (13 times), economic factors (11 times), the physical environment (10 times), cultural influences (10 times), aging of the population (9 times) and sedentary lifestyles (6 times). Finally, when asked about the barriers keeping Hialeah residents from improving their healthy lifestyles a lack of community collaboration was cited the most (16 times), followed by a lack of funding ( 8 times), and a lack of government support (4 times).

When respondents were questioned about what the City does well and what it does poorly to promote physical activity and healthy eating in Hialeah, stakeholders felt that the biggest facilitators were the physical activity programs and opportunities offered by the local park system, as well as healthy options in vending machines for children. Other facilitators included promotion of physical activity campaigns and healthy eating initiatives. On the other hand, barriers to healthy living included poor walkability and unhealthy options at restaurants (Table 2). 
When the stakeholders were asked specifically about the impact of the environment on physical activity levels and healthy eating, community stakeholders felt that the city parks and recreational facilities (cited 9 times) were most conducive and that traffic was the biggest barrier (cited 8 times) to being physically activity. They also felt that automobiles had a strong, negative impact on healthy living in Hialeah. Driving (reliance on cars, too many roads, difficulty crossing the streets, etc.) was cited as a barrier 23 times, followed by safety concerns when walking (6 times), and poor public transportation (6 times). When asked about the walkability of Hialeah, 21 stakeholders responded that the city was not very walkable and suggested that there is a need for wider and more shaded sidewalks. Stakeholders offered few suggestions as to how the food environment was conducive for healthy eating as no response received more than one mention. In contrast, the multitude of unhealthy food options and restaurants that exist in Hialeah were cited multiple times throughout the interviews as being a major barrier to healthy eating in the community.

The final section of the stakeholder interview focused on ways to increase healthy living in Hialeah in the future. Several stakeholders were either unaware of or felt that there was a lack of policies and programs to support healthy living as well as little local media promotion of healthy initiatives. At the same time, several other stakeholders positively pointed to the programs hosted by local community and hospitals (8 times), schools (4 times), and youth centers (3 times) as ways of increasing healthy living. When asked about goals for making Hialeah a healthier community, improvements to parks was cited 10 times, 7 discussed non-specific community/government goals (they were unable to provide concrete examples), while 4 respondents reported that they were unaware of any future goals. To better involve Hialeah citizens in becoming more active and eating healthier, stakeholders felt that there was a need for more education and health information (cited 
12 times), health programs (11 times), media messaging (10 times), greater targeting of the family unit (7 times), increasing access to affordable physical activity programs and healthier foods (5 times), and empowering citizens (2 times).

\section{$\underline{\text { Community Member Responses }}$}

A total of 85 community members participated in the survey. A greater number of respondents were female, between the ages of 45 and 65, had lived in Hialeah between 11 to 20 years, born in Cuba or were of Cuban descent, native Spanish speakers, and had children over the age of 22 (see Table 3).

When asked about the physical activity environment, nearly three-quarters $(72.9 \%)$ of the community members felt that there were sufficient community resources for physical activity and over two-thirds (69.4\%) indicated that they felt that the physical activity environments were accessible and safe. However, less than one-half $(47.0 \%)$ responded that they were aware of community programs in Hialeah to increase physical activity. Approximately three-quarters (74.1\%) of the community members perceived that there was a variety of healthy food and beverage options available to them and two-thirds $(67.9 \%)$ of respondents reported consuming a healthy diet. Over three-quarters of the respondents (76.5\%) indicated that they thought eating healthy is more expensive than eating fast food, while just over half (54.8\%) believed there were sufficient water fountains in public areas. Similar to physical activity programming, only onequarter of the respondents (24.7\%) were aware of community programs in Hialeah to increase healthy eating. One-third (34.1\%) believed there were sufficient programs and/or opportunities to 
teach children and adults about healthy living in Hialeah. Only $41.1 \%$ of the respondents believed there was sufficient positive messaging to promote health in Hialeah.

When asked about their healthcare experiences, a majority (79.8\%) of the respondents felt that it was their healthcare providers' responsibility to advise them about physical activity and healthy eating, and most (73.0\%) reported that their providers had that talk with them about these topics. Almost all (92.9\%) wanted their healthcare provider to refer them to healthy living experts, such as an exercise specialist or nutritionist. Less than six in ten (58.9\%) reported that their employers encouraged healthy lifestyles. Finally, when asked about their perception of the school environment in supporting physical activity and healthy eating in Hialeah, less than half (46.4\%) believed the schools in Hialeah did a good job in educating children about obesity, being active, and eating healthy, $43.4 \%$ felt that Hialeah schools provided healthy food options, and only $40.9 \%$ believed that schools offered a sufficient amount of physical education time.

\section{Differences across Age, Gender, Country of Origin, and Other Characteristics}

There were no significant differences in the responses to the survey questions across the different age groups. While men and women equally agreed that Hialeah had sufficient physical activity environments, females were significantly less likely to feel that these environments were accessible and safe. Similarly, less than half (49.1\%) of the female respondents thought there was a sufficient number of public water fountains compared to two-thirds of male respondents (65.5\%). Significantly more foreign-born respondents believed that there was a variety of healthy food and beverage options available (US: $50.0 \%$, Cuba: $84.1 \%$, other: $78.9 \%$ ). There were no significant 
differences in the survey responses stratified by the number of years that respondents had resided in Hialeah.

Significantly more parents with school-age children (60.9\%) believed that the schools' physical education requirements were sufficient compared to those who did not have school-aged children $(33.3 \%)$. There were no significant differences in responses to the statements "I eat a healthy diet,"

"Eating healthy is more expensive than eating fast food," or "There are sufficient programs and/or opportunities to teach children and adults about healthy living in Hialeah" between participants with and without school-aged children.

\section{Discussion}

The goal of this study was to assess the community health needs of the City of Hialeah from the perspectives of both its community stakeholders and residents. Interviews conducted with the community stakeholders yielded concerns of the overall health for Hialeah residents, such as healthcare and mental health issues, and how cultural influences, combined with the existing food and physical environment, serve as major barriers to achieving healthy lifestyles, particularly in regards to healthy eating. In contrast, community members believed that there are a variety of available healthy food options and resources for physical activity. However, respondents also reported that they were unaware of community programs that encouraged healthy eating, physical activity, and overall health promotion. They also indicated that there was not a high level of positive messaging promoting healthy lifestyles in Hialeah. Both community members and community stakeholders reported that the local park system was a major asset to healthy living in 
Hialeah and all agreed that traffic issues and a lack of walkability were major barriers to physical activity.

Overall, community members believed that Hialeah had sufficient environments where they could be physically active, such as fields, parks, and safe running paths, and that these areas were safe and accessible. However, after stratifying by gender, females were less likely to feel safe in these environments. Several studies have examined the association between neighborhood safety and physical activity, particularly in minority communities. In one study, researchers found that a perceived lack of safety contributed to lower levels of physical activity, especially in women [20]. This may have implications; not only for women, but also for their children as Hispanic mothers' perceptions of safety is associated with their children's physical activity [21]. Although community members agreed that safety in Hialeah, and in the parks, had greatly increased over the past decade, there are additional steps that could be taken to make families feel more secure, such as having more police officers stationed strategically throughout the community.

Both stakeholders and community members regarded city parks as the strongest contributor to physical activity and physical health in Hialeah. However, Hialeah was recently ranked as one of the least active U.S. cities, largely because of the limited number of parks per capita, suggesting a possible disconnect between resident perceptions and unbiased reporting. Stakeholders pointed to initiatives set forth by the park system, including the growth of park and recreation programs, addition of outdoor fitness stations, and the development of bike and walking paths, as potential drivers for developing a healthier community in the future. Another potential strategy may be the development of more "pocket parks." Pockets parks are smaller than typical parks (typically less 
than 1 acre), but serve those in a half-mile radius, and have been found to promote increased physical activity in families [22]. Local parks, and their proximity to residents, have been found to play an influential role in physical activity in minority communities [23].

In addition to the safety of the parks, one of the most discussed issues by the community stakeholders was the traffic hazards and walkability of the city. They commented that the busy roads were unsafe, the intersections were not pedestrian friendly, and the streets cutting through neighborhoods were dangerous. These concerns have the ability to affect physical activity levels among residents as walkability of a neighborhood is closely related to the likelihood of meeting physical activity recommendations by walking [24]. Although the residents in those low socioeconomic status communities had greater spatial access to recreational areas, they perceived their neighborhood to be busier with traffic and less conducive to walking. In another study, lower levels of walking and vigorous physical activity were associated with these same perceptions, as well as modifiable environmental factors, such as neighborhood attractiveness and sidewalk accessibility [25]. A walking program with African-American and Latina women was positively influenced by traffic controls and crossing aides, suggesting that protection from traffic can be just as influential on physical activity, as safety from crime [26].

The community stakeholders mentioned issues regarding healthy eating much more frequently than physical activity. They attributed the Hispanic culture as being a major negative influence on dietary habits and discussed how the Hispanic culture does not focus on eating highly nutritious foods. They also spoke of how foreign-born residents have difficulty adjusting to the availability of cheap, energy dense food in the U.S. Several studies examining the relationship between 
acculturation and dietary intake of Hispanics living in the U.S. suggest that greater acculturation leads to more consumption of fast foods, snacks, sugar sweetened beverages and a higher likelihood of participating in other unhealthy behaviors, such as smoking and being physically inactive [27-28]. In contrast to the stakeholders, the majority of community members reported that they ate a healthy diet despite acknowledging that it is more expensive to purchase healthy options. This dissonance between the community stakeholders and the residents is further highlighted when community members were asked where they bought healthy foods. While stakeholders acknowledged a lack of healthy food options in the community, such as an absence of farmer's markets and healthy restaurants, as a major barrier to healthy eating in Hialeah, community members reported going to local grocery stores or fast foods restaurants for healthy choices; few spoke of the lack of fresh markets and none identified healthy restaurants. Clearly, there appears to be a need to offer greater healthy eating and food options, such as farmers markets, which can be an effective tool for rebuilding local food systems [29], and to better educate residents on what a healthy diet consists of and how to achieve it.

An area of agreement between community stakeholders and members was the low level of messaging and communication around healthy living in Hialeah. The majority of community members were not aware of programs available to them or their children and several stakeholders found it difficult to name available community resources or programs. Stakeholders listed a lack of media, promotion of healthy options, and knowledge/educational efforts as some of the more common barriers to healthy eating. Similarly, a low percentage of community members reported being aware of existing physical activity and healthy eating programs while less than half agreed that there was a sufficient level of positive messaging in Hialeah regarding physical activity and 
healthy eating. Previous studies have reported that health communication campaigns have the ability to affect risky social norms [30], promote healthy eating [31], and encourage physical activity [32]. Furthermore, nutrition campaigns for fruit and vegetable consumption, fat intake, and breastfeeding have been shown to have more success on average than other health topics [33]. It is clear that there is a need for an enhanced level of health communication from the City government and community leaders of ongoing initiatives and programs available to the residents in Hialeah.

\section{Conclusion}

This needs assessment identified several facilitators and barriers to healthy living for the residents of Hialeah. The opinions of the community stakeholders and members have the potential to inform future strategies and address key issues in the community to advance the residents' health. The well-being of Hialeah residents may be improved through greater efforts to improve safety and walkability, communication and health education efforts, and provision of healthier food options. The findings from this assessment can serve as a valuable source of information for city officials and community leaders in developing future strategic plans to enhance the health and wellness of the residents of the City of Hialeah. 


\section{References}

1. U.S. Census Bureau. (2012). Facts for Feature: Hispanic Heritage Month (CB12-FF.19). Washington D.C.: Government Printing Office.

2. U.S. Census Bureau (2012). U.S. Census Bureau Projections Show a Slower Growing, Older, More Diverse Nation a Half Century from Now (CB12-243). Washington D.C.: Government Printing Office.

3. National Institute of Heart, Lung, and Blood Institute. (2013). Hispanic Community Health Study Data Book: A Report to the Communities (NIH Publication No. 13-7951). Bethesda, MD: U.S. Department of Health and Human Services, National Institutes of Health.

4. Heiss, G., Snyder, M.L., Teng Y., et al. (2014). Prevalence of metabolic syndrome among Hispanics/Latinos of diverse background: the Hispanic Community Health Study/Study of Latinos. Diabetes Care, 37(8):2391-9.

5. Centers for Disease Control and Prevention. (2013). CDC Health Disparities and Inequalities Report — United States, 2013. Morbidity and Mortality Weekly Report; 62(Suppl 3):7-18.

6. Department of Health and Human Services, Office of the Assistant Secretary for Planning and Evaluation. (2011). Overview of the Uninsured in the United States: A Summary of the 2011 Current Population Survey. Retrieved from website:

http://aspe.hhs.gov/health/reports/2011/CPSHealthIns2011/ib.pdf

7. Blackwell, D.L., Lucas, J.W., \& Clarke, T.C. (2014). Summary health statistics for U.S. adults: National Health Interview Survey, 2012. National Center for Health Statistics. Vital and Health Statistics; 10(260).

8. Ogden, C.L., Carroll, M.D., Kit, B.K., \& Flegal, K.M. (2014). Prevalence of Childhood and Adult Obesity in the United States, 2011-2012. The Journal of the American Medical Association, 311(8):806-814.

9. Flegal, K.M., Carroll, M.D., Kit, B.K., \& Ogden, C.L. (2012). Prevalence of obesity and trends in the distribution of body mass index among US adults, 1999-2010. The Journal of the American Medical Association; 307(5):491-97.

10. Kaplan, R.C., Avilés-Santa, M.L., Parrinello, C.M. \& et al. (2014). Body Mass Index, Sex, and Cardiovascular Disease Risk Factors Among Hispanic/Latino Adults: Hispanic Community Health Study/Study of Latinos. Journal of the American Heart Association, 3:e000923.

11. Cardemil, E.V., Adams, S.T., \& Calista, J.L. (2007). The Latino Mental Health Project: A Local Mental Health Needs Assessment. Administration and Policy in Mental Health and Mental Health Services Research; 34 (4): 331-41.

12. U.S. Census Bureau: State and County QuickFacts. (2010). Hialeah (city), Florida. Data derived from Population Estimates, American Community Survey, Census of Population and Housing, County Business Patterns, Economic Census, Survey of Business Owners, Building Permits, Census of Governments. Washington D.C.: Government Printing Office.

13. U.S. Census Bureau (2011). The Hispanic Population: 2010 Census Briefs (C2010BR-04). Washington D.C.: Government Printing Office.

14. Modern Language Association. (2010). MLA Data Center Results of Hialeah, FL. Retrieved from 
http://www.mla.org/map_data_results\&state_id=12\&county_id=\&mode=\&zip=\&place_id=30000\&ct y_id $=\& 11=\& a=\& e a=\&$ order $=r$

15. Bernardo, R. (2014) 2014's Best and Worst Cities for an Active Lifestyle. WalletHub. Retrieved from http://wallethub.com/edu/best-and-worst-cities-for-an-active-lifestyle/8817/

16. Professional Research Consultants. (2013) Miami-Dade County Community Health Needs Assessment Household Survey Report. Omaha, Nebraska: PRC, Inc. Retrieved from http://www.healthcouncil.org/wpcontent/uploads/2013/12/2013_PRC_Miami_Dade_County_CHNA_Report_Reduced.pdf

17. Siegel, L.M., Attkisson, C.C., \& Carson, L.G. (1978) Need Identification and Program Planning in the Community context. In C.C. Attkisson (Ed.), Evalutaion of Human Service Program (p. 216). New York, NY : Academic Press, Inc.

18. Rhodes, J.E., Jason, L.A. (1991) Community Needs Assessment. In H.E. Schroeder (Ed.), New Directions in Health Psychology Assessment (p.162). New York, NY: Hemisphere Publishing Corporation.

19. Glickman, D., Parker, L., Sim, L.J, Del Valle Cook, H., \& Miller, E.A. (2012) Accelerating Progress in Obesity Prevention: Solving the Weight of the Nation. Washington, D.C.: The National Academies Press.

20. Bennett, G.G., McNeill, L.H., Wolin, K.Y., Duncan, D.T., Puleo E, et al. (2007) Safe To Walk? Neighborhood Safety and Physical Activity Among Public Housing Residents. PLoS Med; 4(10): e306.

21. Olvera, N, Smith, D.W., Lee,C., \& et al. (2012) Hispanic maternal and children's perceptions of neighborhood safety related to walking and cycling. Health \& Place; 18 (1): 71-75.

22. Cohen, D.A., Marsh, T., Williamson, S., \& et al (2014) The Potential for Pocket Parks to Increase Physical Activity. American Journal of Health Promotion: January/February 2014, 28(sp3): S19-S26.

23. Cohen, D. A., McKenzie, T. L., Sehgal, A., Williamson, S., Golinelli, D., \& Lurie, N. (2007). Contribution of Public Parks to Physical Activity. American Journal of Public Health; 97(3): 509-514.

24. Brown, S.C., Pantin, H., Lombard, J., Toro, M., Huang, S., Plater-Zyberk, E.,... Szapocznik J. (2013) Walk Score ${ }^{\circledR}$ : associations with purposive walking in recent Cuban immigrants. American Journal of Preventive Medicine; 45(2):202-206.

25. Giles-Corti, B., \& Donovan, R.J. (2002) Socioeconomic Status Differences in Recreational Physical Activity Levels and Real and Perceived Access to a Supportive Physical Environment. Preventive Medicine; 35(6): 601-611.

26. Lee, R.E, Mama, SK, Medina, A.V., Ho, A., \& Adamus, H.J. (2012) Neighborhood factors influence physical activity among African American and Hispanic or Latina women. Health Place; 18(1): 63-70.

27. Ayala, G.X., Baquero, B., \& Klinger, S. (2008) A Systematic Review of the Relationship between Acculturation and Diet among Latinos in the United States: Implications for Future Research. Journal of the American Dietetic Association; 108(8): 1330-1344. 
28. Gordon-Larsen, P., Harris, K.M., Ward, D.S., \& Popkin, B.M. (2003) Acculturation and overweight-related behaviors among Hispanic immigrants to the US: the National Longitudinal Study of Adolescent Health. Social Science \& Medicine; 57(11): 2023-2034.

29. Brown, C., \& Miller, S. (2008). The impacts of local markets: a review of research on farmers markets and community supported agriculture (CSA). American Journal of Agricultural Economics, 90(5), 1298-1302.

30. Abroms, L.C., \& Maibach, E.W. (2008) The Effectiveness of Mass Communication to Change Public Behavior. Annual Review of Public Health, 29: 219-34.

31. Reger, B., Wootan, M.G., \& Booth-Butterfield, S. (1999) Using Mass Media to Promote Healthy Eating: A Community-Based Demonstration Project. Preventive Medicine; 29(5): 414-421.

32. Sallis, J.F., Bauman, A., \& Pratt, M. (1998) Environmental and policy interventions to promote physical activity. American Journal of Preventive Medicine; 15(4): 379-397.

33. Snyder, L.B. (2007) Health Communication Campaigns and Their Impact on Behavior. Journal of Nutrition Education and Behavior; 39(2): S32-S40. 
Table 1. Locations where community member surveys were conducted*

\begin{tabular}{|l|l|l|}
\hline Community Parks (8) & Institute of Higher Education (8) & Supermarkets (8) \\
\hline Community Pools (7) & School Setting (6) & Restaurants (6) \\
\hline Healthcare Setting (8) & Library (6) & Chamber of Commerce (1) \\
\hline Fire Department (4) & Religious Settings (6) & Local Non-Profit Organization (5) \\
\hline Housing Authority (8) & $\begin{array}{l}\text { Faith-based Non-Profit Organization } \\
(4)\end{array}$ & \\
\hline
\end{tabular}

* Numbers in parentheses indicate the number of community members that participated from each site. 
Table 2. Community stakeholder responses regarding the facilitators and barriers that promote physical activity and healthy eating*

\begin{tabular}{|l|ll|}
\hline \multicolumn{1}{|c|}{ Facilitators } & \multicolumn{1}{c|}{ Barriers } \\
\hline Physical Activity & \multicolumn{1}{|c|}{} \\
& Parks and trails (19) & Poor walkability (5) \\
& Recreation facilities (4) & Lack of media promotion (5) \\
& Physical activity campaigns (3) & Lack of parks (3) \\
& Organized walking/running events (3) & No bike lanes (2) \\
& Local gyms and exercise classes (3) & Budget cuts (2) \\
& Employee wellness programs (2) & Lack of elderly programs (1) \\
& School \& sport programs (2) & High costs associated with programs (1) \\
& Media promotion (1) & Lack of parental involvement (1) \\
\hline Healthy Eating & & \\
& Promoting healthy snacks for children & Unhealthy options at restaurants (10) \\
& (healthy options in vending machines) (8) & Lack of promotion of healthy options (5) \\
& Nutrition education (5) & Lack of media promotion (3) \\
& Farmer's markets (4) & Lack of farmer's markets (3) \\
& Promotion of healthy eating initiatives (3) & Lack of responsibility among healthcare \\
& More healthy options (2) & professionals/city officials (2) \\
& Street vendors "selling crops" (2) & Lack of collaboration (2) \\
& Marketing and media promotion (1) & Lack of knowledge and education (2) \\
& Community garden (1) & Lack of fresh foods or street vendors \\
& "selling crops" (2) & Cost of healthy eating (1) \\
\hline
\end{tabular}

* Numbers in parentheses indicate the total times a facilitator or barrier was mentioned by the community stakeholders. 
Table 3. Characteristics of the community members who completed the survey

\begin{tabular}{|c|c|c|}
\hline Age & $\mathrm{n}$ & $\%$ of Sample \\
\hline $18-29$ & 17 & $20.0 \%$ \\
\hline $30-44$ years old & 25 & $29.4 \%$ \\
\hline 45-64 years old & 30 & $35.3 \%$ \\
\hline $65+$ years old & 13 & $15.3 \%$ \\
\hline \multicolumn{3}{|l|}{ Gender } \\
\hline Male & 29 & $34.1 \%$ \\
\hline Female & 56 & $65.9 \%$ \\
\hline \multicolumn{3}{|l|}{ Years as a Hialeah Resident } \\
\hline $0-10$ & 31 & $36.5 \%$ \\
\hline $11-30$ & 34 & $40 \%$ \\
\hline $31-41+$ & 20 & $23.5 \%$ \\
\hline \multicolumn{3}{|l|}{ Birth Country } \\
\hline USA & 22 & $25.9 \%$ \\
\hline Cuba & 44 & $51.8 \%$ \\
\hline Other & 19 & $22.3 \%$ \\
\hline \multicolumn{3}{|l|}{ Native Language } \\
\hline English & 14 & $16.5 \%$ \\
\hline Spanish & 71 & $83.5 \%$ \\
\hline \multicolumn{3}{|l|}{ Children } \\
\hline Yes & 61 & $71.8 \%$ \\
\hline No & 24 & $28.2 \%$ \\
\hline \multicolumn{3}{|l|}{ Ages of Children } \\
\hline $0-4$ (preschool) & 12 & $10.2 \%$ \\
\hline 5-11 (preteen) & 19 & $16.1 \%$ \\
\hline $12-17$ (teenager) & 13 & $11.0 \%$ \\
\hline $18-21$ (age of minority to age of majority) & 12 & $10.2 \%$ \\
\hline $22+$ & 62 & $52.5 \%$ \\
\hline
\end{tabular}


Table 4. Community member responses to selected survey questions

\begin{tabular}{|c|c|c|c|c|c|}
\hline & $\begin{array}{c}\text { Strongly } \\
\text { Agree }\end{array}$ & Agree & Neutral & Disagree & $\begin{array}{l}\text { Strongly } \\
\text { Disagree }\end{array}$ \\
\hline $\begin{array}{l}\text { Hialeah has sufficient physical activity environments, } \\
\text { such as fields, parks, and safe running paths. }\end{array}$ & $34(40 \%)$ & $28(32.9 \%)$ & $7(8.2 \%)$ & $15(17.6 \%)$ & $1(1.2 \%)$ \\
\hline $\begin{array}{l}\text { The physical activity environments in Hialeah are } \\
\text { accessible and safe. }\end{array}$ & $22(25.9 \%)$ & $37(43.5 \%)$ & $16(18.8 \%)$ & $8(9.4 \%)$ & $2(2.4 \%)$ \\
\hline $\begin{array}{l}\text { I am aware of community programs that exist in Hialeah } \\
\text { to increase physical activity. }\end{array}$ & $15(17.6 \%)$ & $25(29.4 \%)$ & $14(16.5 \%)$ & $25(29.4 \%)$ & $6(7.1 \%)$ \\
\hline $\begin{array}{l}\text { There are a variety of healthy food and beverage options } \\
\text { available to me in Hialeah. }\end{array}$ & $31(36.5 \%)$ & $32(37.6 \%)$ & $8(9.4 \%)$ & $8(9.4 \%)$ & $6(7.1 \%)$ \\
\hline I eat a healthy diet. & $26(31.0 \%)$ & $31(36.9 \%)$ & $16(19.0 \%)$ & $8(9.5 \%)$ & $3(3.6 \%)$ \\
\hline Eating healthy is more expensive than eating fast food. & $53(62.4 \%)$ & $12(14.1 \%)$ & $9(10.6 \%)$ & $6(7.1 \%)$ & $5(5.9 \%)$ \\
\hline There are sufficient water fountains in public areas. & $24(28.6 \%)$ & $22(26.2 \%)$ & $15(17.9 \%)$ & $17(20.2 \%)$ & $6(7.1 \%)$ \\
\hline $\begin{array}{l}\text { I am aware of community programs that exist in Hialeah } \\
\text { to increase healthy eating. }\end{array}$ & $4(4.7 \%)$ & $17(20.0 \%)$ & $17(20.0 \%)$ & $33(38.8 \%)$ & $14(16.5 \%)$ \\
\hline $\begin{array}{l}\text { There are positive messages to promote health in } \\
\text { Hialeah, such as preventing obesity and becoming more } \\
\text { physically active. }\end{array}$ & $7(8.2 \%)$ & $28(32.9 \%)$ & $14(16.5 \%)$ & $28(32.9 \%)$ & $8(9.4 \%)$ \\
\hline $\begin{array}{l}\text { There are sufficient programs and/or opportunities to } \\
\text { teach children and adults about healthy living in } \\
\text { Hialeah. }\end{array}$ & $7(8.2 \%)$ & $22(25.9 \%)$ & $23(27.1 \%)$ & $26(30.6 \%)$ & $7(8.2 \%)$ \\
\hline $\begin{array}{l}\text { My employer encourages physical activity and healthy } \\
\text { habits for their employees.* }\end{array}$ & $22(32.4 \%)$ & $18(26.5 \%)$ & $6(8.8 \%)$ & $18(26.5 \%)$ & $4(5.9 \%)$ \\
\hline $\begin{array}{l}\text { It is the responsibility of my healthcare provider (such } \\
\text { as my doctor or nurse) to talk to me about physical } \\
\text { activity and nutrition. }\end{array}$ & $32(38.1 \%)$ & $35(41.7 \%)$ & $12(14.3 \%)$ & $5(6.0 \%)$ & $0(0.0 \%)$ \\
\hline $\begin{array}{l}\text { My healthcare provider (such as my doctor or nurse) has } \\
\text { talked to me about the importance of physical activity } \\
\text { and nutrition. }\end{array}$ & $35(41.2 \%)$ & $27(31.8 \%)$ & $7(8.2 \%)$ & $13(15.3 \%)$ & $3(3.5 \%)$ \\
\hline $\begin{array}{l}\text { My healthcare provider should provide me with referrals } \\
\text { to healthy living experts, such as an exercise specialist } \\
\text { or a nutritionist. }\end{array}$ & $46(54.1 \%)$ & $33(38.8 \%)$ & $4(4.7 \%)$ & $2(2.4 \%)$ & $0(0.0 \%)$ \\
\hline $\begin{array}{l}\text { Schools in Hialeah do a good job educating children } \\
\text { about obesity, being physically active, and healthy } \\
\text { eating. }\end{array}$ & $20(23.8 \%)$ & $19(22.6 \%)$ & $26(31.0 \%)$ & $12(14.3 \%)$ & $7(8.3 \%)$ \\
\hline $\begin{array}{l}\text { Current physical education requirements at schools in } \\
\text { Hialeah provide enough physical activity time for } \\
\text { children. }\end{array}$ & $10(12.0 \%)$ & $24(28.9 \%)$ & $22(26.5 \%)$ & $21(25.3 \%)$ & $6(7.2 \%)$ \\
\hline $\begin{array}{l}\text { Schools in Hialeah do a good job providing healthy and } \\
\text { nutritious food options. }\end{array}$ & $15(18.1 \%)$ & $21(25.3 \%)$ & $26(31.3 \%)$ & $13(15.7 \%)$ & $8(9.6 \%)$ \\
\hline
\end{tabular}

* All survey items consist of 85 community members responses except for this question in which only the 70 employed individuals were asked to respond. 